\title{
Rivaroxaban for a Patient with Class III Obesity: Case Report with Literature Review
}

\author{
Duane Bates, Jenny Edwards, Jeffrey Shrum, Casey Chan, Sharita Manga, and Elizabeth MacKay
}

\section{INTRODUCTION}

$\mathrm{B}$ etween 1985 and 2011, the prevalence of obesity, defined as body mass index (BMI) of $30 \mathrm{~kg} / \mathrm{m}^{2}$ or higher, increased from $6.1 \%$ to $18.3 \%$ in Canada. ${ }^{1}$ It is estimated that by 2019 , more than $55 \%$ of the adult Canadian population will be overweight or obese. ${ }^{1}$ Obesity is associated with an approximately 2-fold increased risk of venous thromboembolism (VTE). ${ }^{2}$ The major mechanisms proposed as being responsible for obesityassociated thrombosis are chronic inflammation, impaired fibrinolysis, and clinical factors such as immobility, obstructive sleep apnea, heart failure, and venous stasis. ${ }^{2}$ Direct oral anticoagulants (DOACs) are indicated for the prevention of acute VTE in patients who have undergone elective hip or knee replacement, for the treatment of acute VTE, for the prevention of recurrent VTE, and for the prevention of stroke or systemic embolism in patients with atrial fibrillation. The Canadian rivaroxaban product monograph states that for patients with extremes of body weight ( $<50 \mathrm{~kg}$ or $>120 \mathrm{~kg}$ ), a 10 -mg tablet caused less than a $25 \%$ change in the plasma concentration of rivaroxaban, and thus no dosage adjustment is required. ${ }^{3}$ The 2016 guidelines of the International Society on Thrombosis and Haemostasis (ISTH) suggest that DOACs not be used in patients with weight greater than $120 \mathrm{~kg}$ or BMI greater than $40 \mathrm{~kg} / \mathrm{m}^{2}$ because of the lack of clinical data for this population. ${ }^{4}$ We present here a case of rivaroxaban use in a patient with class III obesity and review the evidence for use of this medication in obese patients.

\section{CASE REPORT}

A 67-year-old woman with class III obesity (height $160 \mathrm{~cm}$, weight $186.6 \mathrm{~kg}$, BMI $73 \mathrm{~kg} / \mathrm{m}^{2}$ ) was admitted to hospital for hypoxia secondary to a viral illness and heart failure. Her medical history included diabetes mellitus, hypertension, atrial fibrillation, heart failure, chronic kidney disease, dyslipidemia, hypothyroidism, anemia, over-active bladder, chronic back pain, and gastroesophageal reflux disease. Medications before admission included candesartan $8 \mathrm{mg}$ daily, diltiazem ER $180 \mathrm{mg}$ daily, furosemide $40 \mathrm{mg}$ daily, rivaroxaban $20 \mathrm{mg}$ daily, rosuvastatin $10 \mathrm{mg}$ daily, levothyroxine $212 \mu \mathrm{g}$ daily, insulin glargine 24 units at bedtime, insulin lispro 4 units 3 times daily before meals, metformin $500 \mathrm{mg}$ at breakfast and $1000 \mathrm{mg}$ at lunch and supper, pantoprazole $40 \mathrm{mg}$ daily, tolterodine ER $4 \mathrm{mg}$ daily, cholecalciferol 3000 units daily, and tramadol $37.5 \mathrm{mg} /$ acetaminophen $325 \mathrm{mg} 2$ tabs 3 times daily as needed. The patient denied use of other over-the-counter or herbal medications.

The patient had no known drug allergies and stated that she was intolerant of warfarin. More specifically, she reported that she had been given warfarin (for atrial fibrillation) more than 10 years before the current admission but had stopped this medication because her international normalized ratio (INR) was labile and the medication made her feel unwell; however, she could not remember the specific intolerance. The patient stated that acetylsalicylic acid $81 \mathrm{mg}$ daily was then prescribed. A review of prescription records showed that 3.6 years before the current admission, this therapy had been changed to rivaroxaban $\left(\mathrm{CHADS}_{2}\right.$ score 3 and HAS-BLED score 1).

Transthoracic echocardiography 30 days before the admission showed mild concentric left ventricular hypertrophy with normal left ventricular systolic function. Right ventricular systolic function was mildly reduced. Fibrocalcific degenerative changes of the mitral valve leaflets and mild mitral stenosis were noted. The left and right atria were of normal size. No other evidence of valvular disease was noted.

Vital signs upon admission were blood pressure $115 / 85 \mathrm{~mm} \mathrm{Hg}$, heart rate 94 beats $/ \mathrm{min}$, temperature $36.7^{\circ} \mathrm{C}$, respiratory rate 24 breaths $/ \mathrm{min}$, and oxygen saturation $93 \%$ on $10 \mathrm{~L} / \mathrm{min}$ of oxygen. The physical examination showed mild pedal edema, and the respiratory examination showed wheezing and diffuse crackles bilaterally through all fields. Other physical 
findings were unremarkable. Electrocardiography revealed atrial fibrillation, with a rapid ventricular rate of 156 beats $/ \mathrm{min}$. Chest radiography showed bilateral pulmonary edema.

Laboratory test results included serum creatinine $143 \mu \mathrm{mol} / \mathrm{L}$ (normal range 35-100 $\mu \mathrm{mol} / \mathrm{L}$ ) and estimated creatinine clearance $(\mathrm{CrCl}) 52 \mathrm{~mL} / \mathrm{min}$ based on the Cockcroft-Gault calculation with adjustment for body weight (baseline serum creatinine $130-140 \mu \mathrm{mol} / \mathrm{L}$ ). On admission, liver enzymes were normal, except for slight elevation of $Y$-glutamyl transferase to 63 units/L (normal range 0-35 units/L). Pneumonia, influenza, and thrombosis were ruled out as the cause of the patient's shortness of breath. All home medications were continued during the admission.

The clinical team had a discussion with the patient about the lack of evidence to support the use of rivaroxaban in patients with obesity. The patient was made aware that rivaroxaban might not be reducing her risk of stroke or systemic embolism, but she declined switching to warfarin or any other anticoagulant. The patient gave informed consent to have samples drawn for determination of peak and trough anti-factor Xa levels and for publication of this case report.

During the admission, all doses of rivaroxaban were administered at 0800 with breakfast. Rivaroxaban anti-Xa levels were measured with a chromogenic anti-Xa assay using STA-Liquid Anti-Xa (competitive chromogenic assay for factor Xa inhibition) and STA-Rivaroxaban Calibrator (high-performance liquid chromatography-referenced calibration plasmas for rivaroxaban) on the STA-r Evolution analyzer (analyzer and calibrator: Diagnostica Stago S.A.S., Asnières-sur-Seine, France). The rivaroxaban concentration was reported in nanograms per millilitre $(\mathrm{ng} / \mathrm{mL})$, according to calibration of anti-Xa level using the rivaroxaban calibrator. There is no anti-Xa reference range defining the efficacy and safety of rivaroxaban. On day 10 of the admission, peak rivaroxaban concentration measured $3.5 \mathrm{~h}$ after a dose was $465 \mathrm{ng} / \mathrm{mL}$. On day 15 , trough rivaroxaban concentration measured $23.5 \mathrm{~h}$ after the previous dose was $92 \mathrm{ng} / \mathrm{mL}$. The patient was discharged on day 15, with continuation of rivaroxaban $20 \mathrm{mg}$ daily. Four months after discharge the patient continued to take rivaroxaban with no evidence of stroke or systemic embolism.

\section{DISCUSSION}

To understand the implications of rivaroxaban therapy in this patient, certain aspects of the drug's pharmacokinetics must be reviewed. According to Mueck and others, ${ }^{5}$ rivaroxaban is absorbed rapidly, with peak plasma concentrations $\left(C_{\max }\right)$ occurring within $2-4 \mathrm{~h}$. The bioavailability of a 20 -mg tablet is $66 \%$ under conditions of fasting, and the area under the curve (AUC) increases by 39\% when rivaroxaban is taken with food. There is no influence on pharmacokinetics by type of food (high-fat versus high-carbohydrate meal). The volume of distribution is about $0.62 \mathrm{~L} / \mathrm{kg}$, which indicates low-to-moderate affinity for the peripheral tissues. ${ }^{5}$ One-third of each dose of rivaroxaban is excreted unchanged in the urine, with the remaining two-thirds of each dose being subject to metabolic degradation. The resulting metabolites are eliminated both renally and via the hepatobiliary route. ${ }^{5}$ In the case reported here, rivaroxaban was administered once daily with breakfast to maximize absorption. The sample for determination of peak concentration was drawn within the 2- to 4-h window in which rivaroxaban peaks in the blood. As noted above, the drug does not have a high volume of distribution, which suggests that it is not extensively distributed into fat. The patient did not require a reduction in rivaroxaban dose because of renal function.

Our literature search identified only one pharmacokinetic study evaluating rivaroxaban in patients with obesity. This small (48 healthy participants), single-centre, randomized, singleblind, placebo-controlled study was conducted to study the influence of body weight on rivaroxaban pharmacokinetics. ${ }^{6}$ Patients were classified by weight ( $\leq 50 \mathrm{~kg}, 70-80 \mathrm{~kg},>120 \mathrm{~kg}$ ). The average BMI among patients weighing more than $120 \mathrm{~kg}$ was $43.5 \mathrm{~kg} / \mathrm{m}^{2}$ (standard deviation [SD] $4.2 \mathrm{~kg} / \mathrm{m}^{2}$ ). Twelve participants in each study arm received a single dose of rivaroxaban $10 \mathrm{mg}$, and 4 patients in each arm received placebo. The bioavailability, time to $C_{\max }$, and AUC were similar in all weight groups. Rivaroxaban inhibited factor Xa activity to a similar extent in all 3 weight groups. ${ }^{6}$ On the basis of these results, the authors proposed that rivaroxaban is unlikely to require dose adjustment according to body weight. The dose of rivaroxaban used in this study, ${ }^{6} 10 \mathrm{mg}$ daily, is typically used to prevent VTE after total hip or total knee replacement or as thromboprophylaxis in medically ill patients. ${ }^{3,7}$ At BMI $73 \mathrm{~kg} / \mathrm{m}^{2}$, the patient in our case was much larger than the healthy participants studied by Kubitza and others, ${ }^{6}$ and she was receiving a higher dose of rivaroxaban $(20 \mathrm{mg}$ daily) for a different indication (stroke prevention secondary to atrial fibrillation).

Randomized controlled trials of DOACs including a total of more than 71000 patients have shown that fixed-dose, unmonitored therapy is at least as effective as dose-adjusted warfarin for stroke prevention and is associated with less major bleeding, particularly decreased intracranial bleeding. ${ }^{8}$ Routine monitoring and dose adjustments of DOACs cannot be recommended on the basis of available information. Measurement of drug concentration or anticoagulant effect might be useful in certain clinical scenarios, such as major bleeding or thrombotic events, to establish the optimal timing of surgery or other invasive procedures, and to detect drug accumulation in patients with renal or hepatic insufficiency or suspected overdose. ${ }^{8,9}$ Other indications for monitoring may include subtherapeutic or supratherapeutic levels secondary to extremes of body weight, to identify candidates for specific reversal agents, and to assist 
in the management of drug interactions with DOACs. ${ }^{8,9}$ Median trough levels of DOACs may vary by a factor of 6 to 11 among individual patients. ${ }^{8}$ Within-patient variability, expressed as the coefficient of variation, ranges between $20 \%$ and $50 \%$, depending on the population and whether sampling is done at peak or trough. ${ }^{8}$ Measurement of drug concentration or anticoagulant effect is problematic because there are no defined therapeutic ranges for DOACs, and very few laboratories have anti-Xa assays calibrated for rivaroxaban, apixaban, and edoxaban. ${ }^{4,9}$

The ISTH recommends that DOACs not be used in patients with BMI above $40 \mathrm{~kg} / \mathrm{m}^{2}$ or body weight above $120 \mathrm{~kg}$, because of the limited clinical pharmacokinetic and pharmacodynamic data suggesting possible decreased drug exposures, reduced $C_{\max }$, and shorter half-life with increasing weight. This recommendation raises the concern of underdosing in obese patients. ${ }^{4}$ If DOACs are used for patients with BMI above $40 \mathrm{~kg} / \mathrm{m}^{2}$ or body weight above $120 \mathrm{~kg}$, determination of peak and trough anti-Xa levels for rivaroxaban, apixaban, and edoxaban or measurement of drug concentration by mass spectrometry is suggested. If either falls within the expected range (based on the literature), then the DOAC may be continued. However, if either falls below the expected range, then a switch to an oral vitamin $\mathrm{K}$ antagonist should be considered, rather than adjustment of the DOAC dose. ${ }^{4}$ Review of the literature suggests average reported ranges for rivaroxaban concentrations are peak $173-467 \mathrm{ng} / \mathrm{mL}$ and trough $17-94 \mathrm{ng} / \mathrm{mL}$, with wide interpatient variation. ${ }^{5,10-18}$ The range in concentration is similar whether measured by mass spectrometry or anti-Xa. These concentrations have not been correlated with clinical outcomes such as VTE or bleeding. The patient in our case had rivaroxaban peak and trough concentrations at the higher end of these ranges, and the rivaroxaban was therefore continued upon discharge.

A search of PubMed, Embase, and Google Scholar from inception to August 2017 using the search terms "rivaroxaban" and "obesity" yielded 2 case reports of rivaroxaban use in patients with class III obesity. The first case involved a 27-yearold woman who received the anticoagulant phenprocoumon for recurrent deep vein thrombosis with subsequent labile INRs. ${ }^{19}$ No other medications were reported. The peak BMI was $61 \mathrm{~kg} / \mathrm{m}^{2}$, which led to bariatric surgery. Two months after the surgery, the patient was admitted to hospital with INR above 9. The phenprocoumon was discontinued, and rivaroxaban $20 \mathrm{mg}$ daily was initiated. Anti-Xa levels were measured at 3, 6, 12, and $24 \mathrm{~h}$ after the first dose, and again $3 \mathrm{~h}$ after the second dose. The rivaroxaban concentrations at $3 \mathrm{~h}$ after the first and second doses were $224.22 \mathrm{ng} / \mathrm{mL}$ and $262.46 \mathrm{ng} / \mathrm{mL}$, respectively. The trough concentration $24 \mathrm{~h}$ after the first dose was $35.54 \mathrm{ng} / \mathrm{mL}$. Serum creatinine, liver enzymes, and other medications were not reported. ${ }^{19}$ The effect of rivaroxaban could have been diminished because of potential erratic absorption of the drug after the bariatric surgery and low caloric intake in the immediate postoperative period. ${ }^{20,21}$ There is limited evidence concerning the use of DOACs in patients who have undergone major gastrointestinal tract surgery. ${ }^{22}$

The second case involved a 67-year-old man with ischemic stroke, BMI $40 \mathrm{~kg} / \mathrm{m}^{2}$, and $\mathrm{CrCl} 132 \mathrm{~mL} / \mathrm{min}^{23}$ The patient was started on dabigatran $150 \mathrm{mg}$ twice daily. The patient's other medications included bisoprolol and atorvastatin. Seven days after initiation, dabigatran concentration was measured with a thrombin inhibitor assay immediately before and 2, 4, and $6 \mathrm{~h}$ after the morning dose. The authors noted that the drug concentration never reached the interquartile range for $C_{\max }$ and was below the quartile range for trough level. The patient's anticoagulation was changed to rivaroxaban $20 \mathrm{mg}$ daily. Five days after initiation, peak and trough rivaroxaban concentrations were $200 \mathrm{ng} / \mathrm{mL}$ and $30 \mathrm{ng} / \mathrm{mL}$, respectively. ${ }^{23}$ In both of these cases, ${ }^{19,23}$ the patients were not followed over the long term to evaluate the safety and efficacy of rivaroxaban therapy. In the case reported here, the peak concentration was about 2 -fold higher and the trough concentration 3-fold higher than the 2 cases summarized above.

Mass spectrometry and anti-Xa determination show high interpatient variability for a given dose, as well as high variability among populations with different indications for anticoagulation (see Table 1), ${ }^{5,10-18}$ In the case reported here, rivaroxaban peak concentration was measured $3.5 \mathrm{~h}$ after a dose $(465 \mathrm{ng} / \mathrm{mL}$ ) and trough concentration $23.5 \mathrm{~h}$ after the previous dose $(92 \mathrm{ng} / \mathrm{mL})$. The case series by Martin and Moll ${ }^{13}$ most closely relates to the case presented here, but it lacks certain pertinent information. In that series, 15 patients received rivaroxaban: $20 \mathrm{mg}$ daily for 12 patients (summarized in Table 1), $15 \mathrm{mg}$ twice daily for 2 patients, and $15 \mathrm{mg}$ daily for 1 patient. All but 4 of the patients had estimated glomerular filtration rate (eGFR) above $60 \mathrm{~mL} \mathrm{~min}^{-1} 1.73 \mathrm{~m}^{-2}$; of the remaining 4 patients, 3 had eGFR between 30 and $60 \mathrm{~mL}$ $\mathrm{min}^{-1} 1.73 \mathrm{~m}^{-2}$ and 1 had eGFR of $11 \mathrm{~mL} \mathrm{m^{-1 }} 1.73 \mathrm{~m}^{-2}$ (eGFR values were not reported for individual patients). The main reason for determining anti-Xa levels was extremes of body weight: obesity in 7 patients and low body weight in 1 patient. The mean age was 42.6 years (SD 13.4), with weight ranging from $44.5 \mathrm{~kg}$ to $203.9 \mathrm{~kg}$ (median $106.2 \mathrm{~kg}$ ). Peak and trough anti-Xa levels were determined for only some of the patients, and the timing of anti-Xa levels in relation to rivaroxaban administration was not consistently reported. Of the 2 patients who received rivaroxaban $15 \mathrm{mg}$ twice daily, one had a trough rivaroxaban concentration of 0 at $17 \mathrm{~h}$ after dosing, and the other had peak rivaroxaban concentration of $161.6 \mathrm{ng} / \mathrm{mL}$. The patient who received rivaroxaban $15 \mathrm{mg}$ daily had 3 samples drawn for determination of peak concentrations, with values reported as $5.8 \mathrm{ng} / \mathrm{mL}, 116 \mathrm{ng} / \mathrm{mL}$, and $155.5 \mathrm{ng} / \mathrm{mL}$. There 


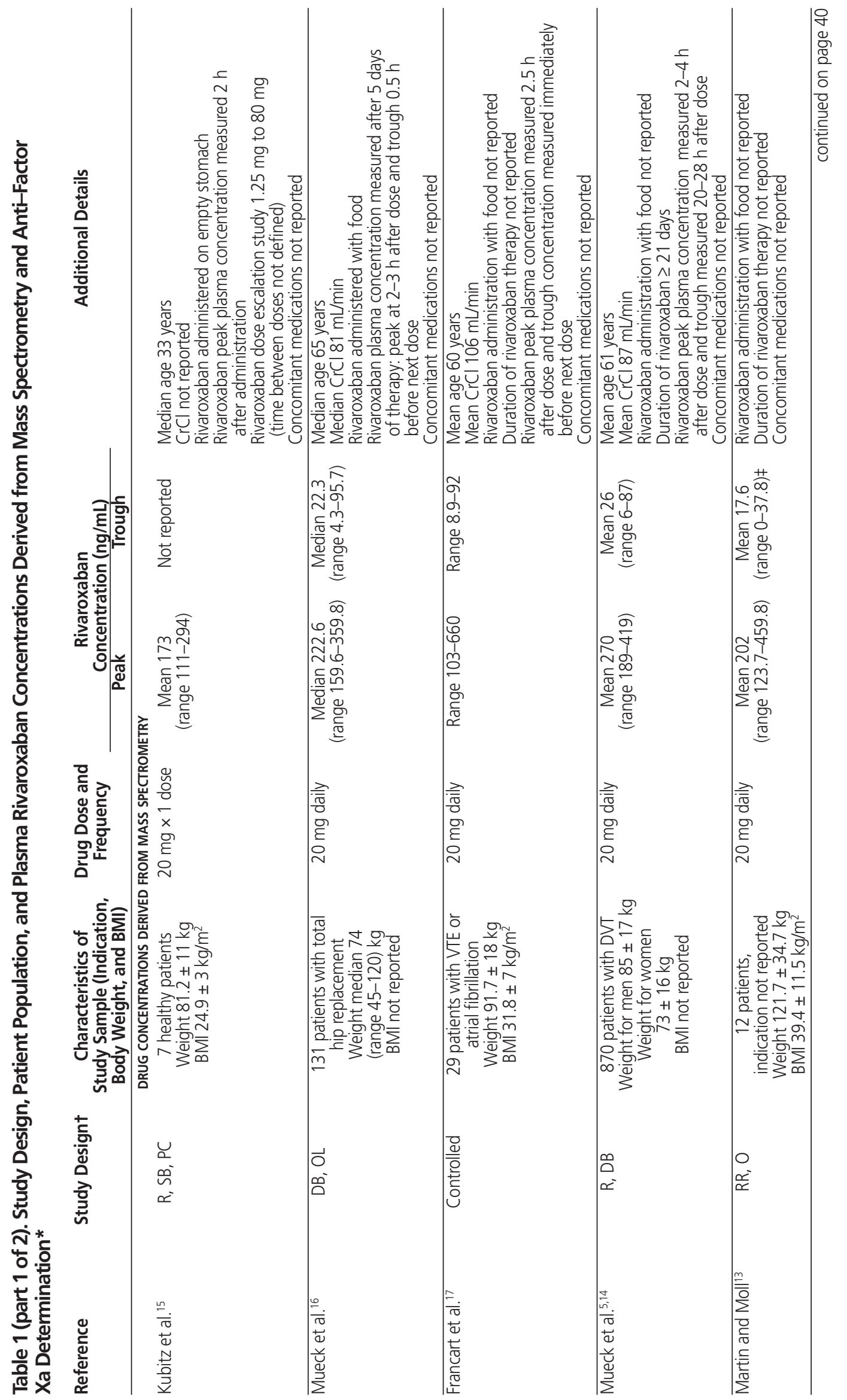




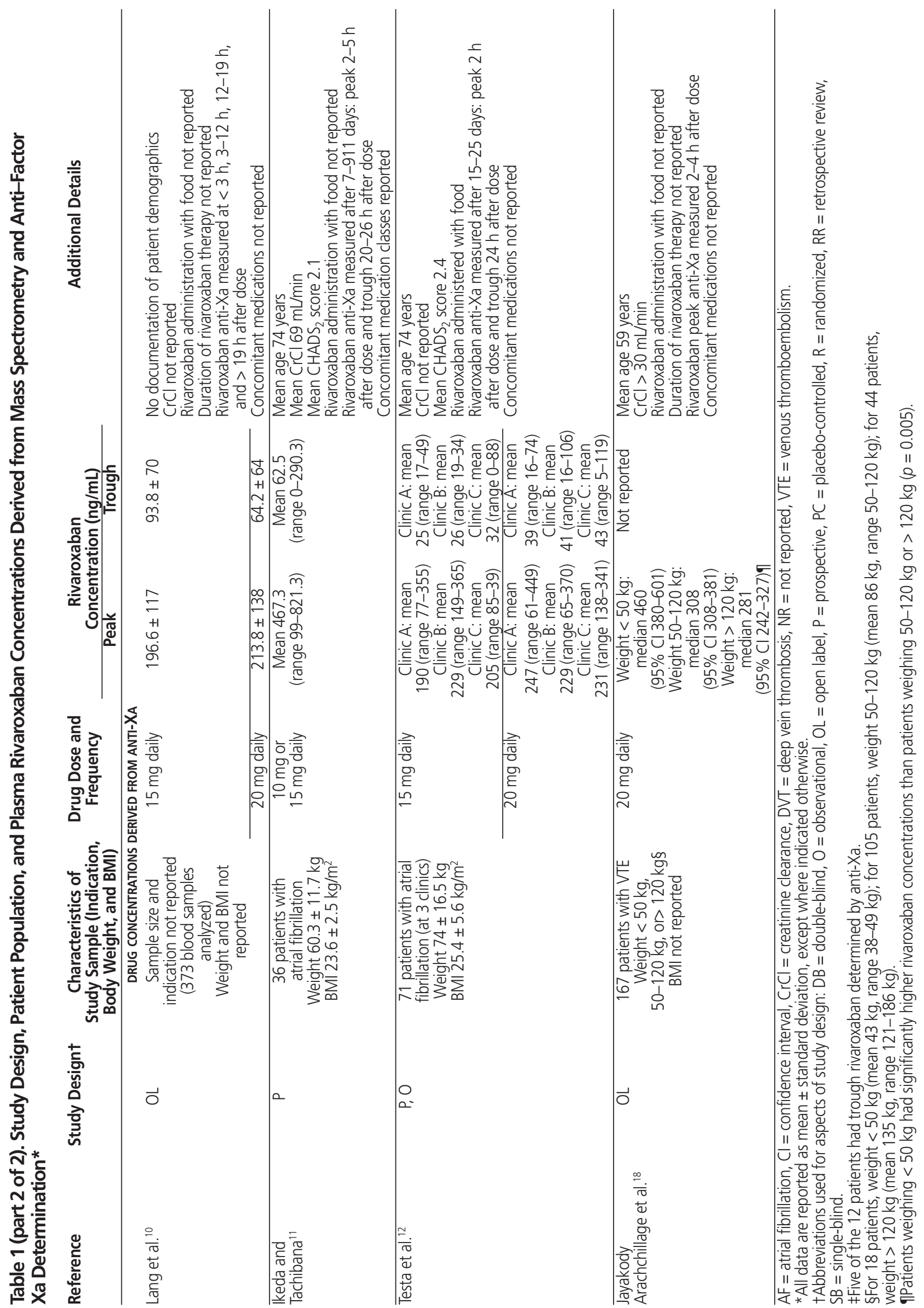


This single copy is for your personal, non-commercial use only.

For permission to reprint multiple copies or to order presentation-ready copies for distribution, contact CJHP at publications@cshp.ca

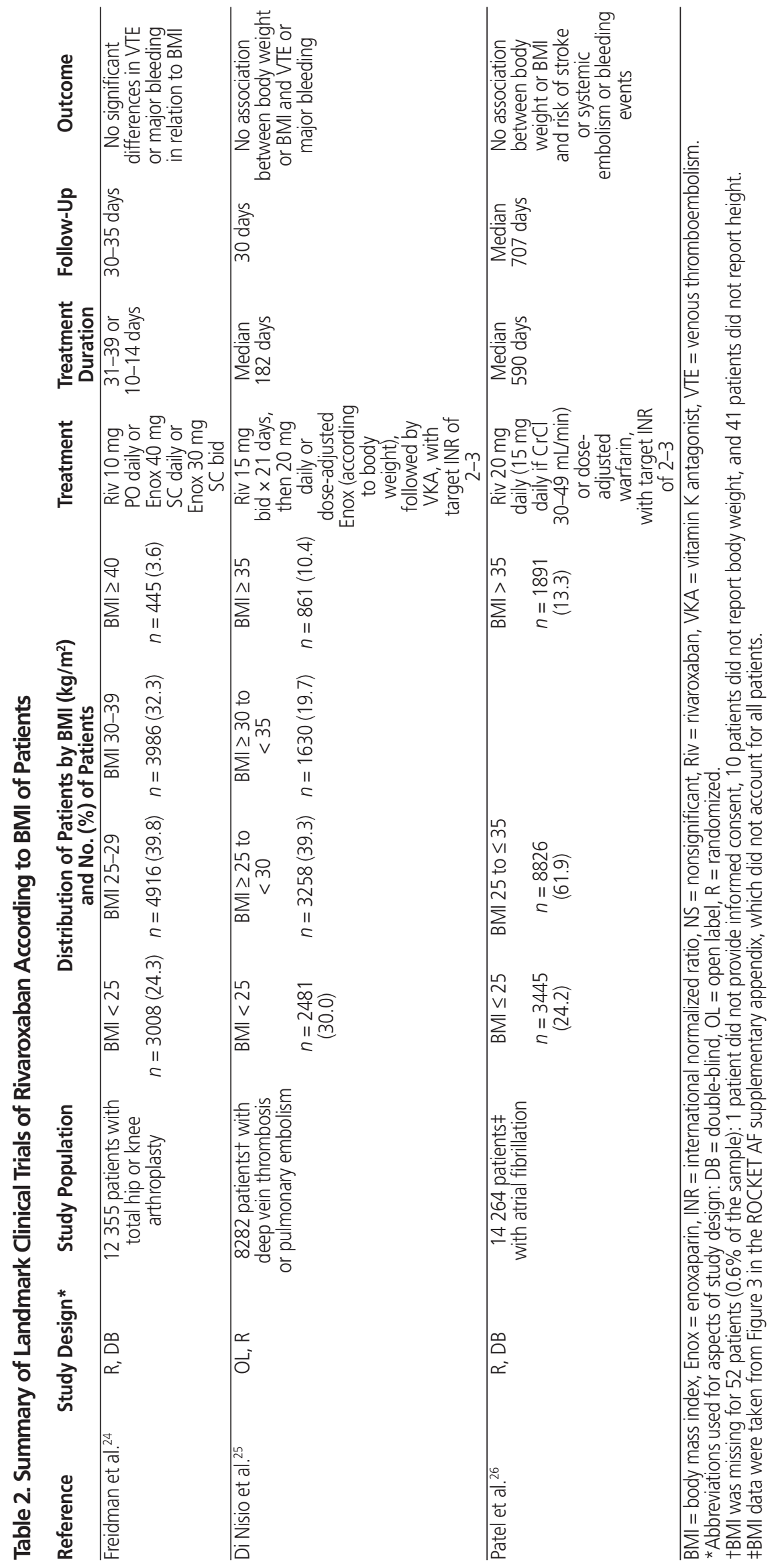


was no change to rivaroxaban therapy in the 15 patients. Overall, the trough concentrations were 5-fold lower and peak concentrations 2-fold lower than in the patient described in our case report.

Patients with obesity have been underrepresented in landmark rivaroxaban clinical trials (Table 2). ${ }^{24-26}$ There were no significant differences in VTE or major bleeding in relation to BMI, but these trials were not powered to consider efficacy and safety outcomes between patients with and without obesity. Of these trials, ROCKET $\mathrm{AF}^{26}$ was the one most similar to our case. The median BMI in ROCKET AF was $28.2 \mathrm{~kg} / \mathrm{m}^{2}$ (interquartile range $25.2-32 \mathrm{~kg} / \mathrm{m}^{2}$ ), whereas the patient in our case had BMI $73 \mathrm{~kg} / \mathrm{m}^{2}$. A subgroup analysis in ROCKET AF showed no significant difference $(p=0.537)$ in stroke or systemic embolism among patients with BMI above $35 \mathrm{~kg} / \mathrm{m}^{2}$ relative to patients with lower BMI. ${ }^{26}$

A post hoc analysis of the ROCKET AF trial by Balla and others ${ }^{27}$ compared the incidence of stroke and systemic embolism in normal-weight patients (BMI 18.5-24.99 kg/m²), overweight patients (BMI 25.00-29.99 kg/m²), and obese patients $\left(\mathrm{BMI} \geq 30 \mathrm{~kg} / \mathrm{m}^{2}\right)$. Over 2 years, the rate of stroke and systemic embolism per 100 patient-years was 3.05 in normalweight patients $(n=3289), 2.34$ in overweight patients $(n=5535$; hazard ratio [HR] $0.77,95 \%$ confidence interval [CI] $0.62-0.95, p=0.013)$, and 1.90 in obese patients $(n=5206$; HR 0.62, 95\% CI 0.50-0.78, $p<0.001) .^{27}$ Overweight and obese patients had significantly lower risk of stroke than normal-weight patients, even after adjustment for hypertension, diabetes, congestive heart failure, prior stroke or transient ischemic attack, age, sex, and serum creatinine (overweight patients, HR 0.79, 95\% CI 0.64-0.98, $p=0.029$; obese patients, HR $0.66,95 \%$ CI $0.53-0.84, p<0.001) .{ }^{27}$ There is no clear explanation for this observation; it is possible that patients with higher body weight might receive optimal cardiac medications more often than those without high body weight, resulting in a lower risk of thromboembolic and cardiovascular outcomes. $^{28}$

\section{CONCLUSION}

There is very little evidence to guide clinicians on the use of rivaroxaban in patients with class III obesity. To the authors' knowledge, this is the first published case reporting use of rivaroxaban in a patient with BMI over $70 \mathrm{~kg} / \mathrm{m}^{2}$. In this case, the peak and trough rivaroxaban concentrations were at the higher end of the ranges reported in the literature. The patient remained on rivaroxaban $20 \mathrm{mg}$ daily for about 4 years with no clinical evidence of stroke or systemic embolism. In the previous literature, use of rivaroxaban in obese patients with hip or knee arthroplasty, VTE, and atrial fibrillation did not suggest decreased efficacy or increased bleeding. However, these conclusions were based on subgroup analyses; the trials were not powered to compare outcomes in patients with and without obesity. Current ISTH guidelines suggest that DOACs not be used in patients with BMI above $40 \mathrm{~kg} / \mathrm{m}^{2}$ or weight greater than $120 \mathrm{~kg}$; however, if rivaroxaban, apixaban, or edoxaban are used, measurement of peak and trough anti-Xa levels or determining drug concentration by mass spectrometry may be considered. If the levels are within the average ranges reported in the literature, therapy may be continued. Randomized controlled trials evaluating the efficacy and safety of rivaroxaban use in obese patients are needed.

\section{References}

1. Twells LK, Gregory DM, Reddigan J, Midodzi WK. Current and predicted prevalence of obesity in Canada: a trend analysis. CMAJ Open. 2014; 2(1):E18-26.

2. Lentz SR. Thrombosis in the setting of obesity or inflammatory bowel disease. Blood. 2016;128(20):2388-94.

3. Xarelto [product monograph]. Mississauga (ON): Bayer Inc; 2015 Jul 20.

4. Martin K, Beyer-Westendorf J, Davidson BL, Huisman MV, Sanset PM, Moll S. Use of direct oral anticoagulants in obese patients: guidance from the SSC of the ISTH. J Thromb Haemost. 2016;14(6):1308-13.

5. Mueck W, Stampfuss J, Kubitza D, Becka M. Clinical pharmacokinetic and pharmacodynamics profile of rivaroxaban. Clin Pharmaokinet. 2014; 53(1):1-16.

6. Kubitza D, Becka M, Zuehlsdorf M, Mueck W. Body weight has limited influence on the safety, tolerability, pharmacokinetics, or pharmacodynamics of rivaroxaban (BAY 59-7939) in healthy subjects. J Clin Pharmacol. 2007; 47(2):218-26.

7. Cohen AT, Spiro TE, Büller HR, Haskell L, Hu D, Hull R, et al. Rivaroxaban for thromboprophylaxis in acutely ill medical patients. NEngl J Med. 2013; 368(6):513-23.

8. Eikelboom JW, Quinlan DJ, Hirsh J, Connolly SJ, Weitz JI. Laboratory monitoring of non-vitamin $\mathrm{K}$ antagonist oral anticoagulant use in patients with atrial fibrillation: a review. JAMA Cardiol. 2017;2(5):566-74.

9. Conway SE, Hwang AY, Ponte CD, Gums JG. Laboratory and clinical monitoring of direct oral anticoagulants: what clinicians need to know. Pharmacotherapy. 2017;37(2):236-48.

10. Lang K, Patel J, Chitongo P, Czuprynska J, Roberts L, Patel R, et al. Real-world rivaroxaban levels from King's College Hospital [abstract]. J Thromb Haemost. 2015;13 Suppl 2:117-8.

11. Ikeda $\mathrm{K}$, Tachibana $\mathrm{H}$. Clinical implication of monitoring rivaroxaban and apixaban by using anti-factor Xa assay in patients with non-valvular atrial fibrillation. J Arrhythm. 2016;32(1):42-50.

12. Testa S, Tripodi A, Legnani C, Pengo V, Abbate R, Dellanoce C, et al. Plasma levels of direct oral anticoagulants in real life patients with atrial fibrillation: results observed in four anticoagulation clinics. Thromb Res. 2016;137: 178-83.

13. Martin K, Moll S. Direct oral anticoagulant drug level testing in clinical practice: a single institution experience. Thromb Res. 2016;143:40-4.

14. Mueck W, Lensing AWA, Agnelli G, Décousus H, Prandomi P, Misselwitz F. Rivaroxaban: population pharmacokinetic analysis in patients treated for acute deep-vein thrombosis and exposure simulations inpatients with atrial fibrillation treated for stroke prevention. Clin Pharmacokinet. 2011;50(10): 675-86.

15. Kubitz D, Becka M, Voith B, Zuehlsdorf M, Wensing G. Safety, pharmacodynamics, and pharmacokinetics of single doses of BAY 59-7939, an oral, direct factor Xa inhibitor. Clin Pharmacol Ther. 2005;78(4):412-21.

16. Mueck W, Borris LC, Dahl OE, Haas S, Huisman MV, Kakkar AK, et al. Population pharmacokinetics and pharmacodynamics of once and twicedaily rivaroxaban for the prevention of venous thromboembolism in patients undergoing total hip replacement. Thromb Haemost. 2008;100(3):453-61.

17. Francart SJ, Hawes EM, Deal AM, Adcock DM, Gosselin R, Jeanneret C, et al. Performance of coagulation tests in patients on therapeutic dose of rivaroxaban. Thromb Haemost. 2014;111(6):1133-40. 
This single copy is for your personal, non-commercial use only.

For permission to reprint multiple copies or to order presentation-ready copies for distribution, contact CHHP at publications@cshp.ca

18. Jayakody Arachchillage D, Reynolds R, Devey T, Maclean R, Kitchen S, Van Veen J. Effect of extremes of body weight on efficacy and safety of rivaroxaban in the treatment of venous thromboembolism: real life experience [abstract]. J Thromb Haemost. 2016;14 Suppl 1:8.

19. Mahlmann A, Gehrisch S, Beyer-Westendorf J. Pharmacokinetics of rivaroxaban after bariatric surgery: a case report. J Thromb Thrombolysis. 2013; 36(4):533-5.

20. Thomas $Z$, Bareket $Y$, Bennett $W$. Rivaroxaban use following bariatric surgery [letter]. J Thromb Thrombolysis. 2014;38(1):90-1.

21. Bland CM, Quidley AM, Love BL, Yeager C, McMichael B, Bookstaver PB. Long-term pharmacotherapy considerations in the bariatric surgery patient. Am J Health Syst Pharm. 2016;73(16):1230-42.

22. Hakeam HA, Al-Sanea N. Effect of major gastrointestinal tract surgery on the absorption and efficacy of direct oral acting anticoagulants (DOACs). J Thromb Thrombolysis. 2017;43(3):343-51.

23. Safouris A, Demulder A, Triantafyllou N, Tsivgoulis G. Rivaroxaban presents a better pharmacokinetic profile than dabigatran in an obese non-diabetic stroke patient [letter]. J Neurol Sci. 2014;346(1-2):366-7.

24. Freidman RJ, Hess S, Berkowitz SD, Homering M. Complication rates after hip or knee arthroplasty in morbidly obese patients. Clin Orthop Relat Res. 2013;471(10):3358-66

25. Di Nisio M, Vedovati MC, Riera-Mestre A, Prins MH, Mueller K, Cohen AT, et al. Treatment of venous thromboembolism with rivaroxaban in relation to body weight: a sub-analysis of the EINSTEIN DVT/PE studies. Thromb Haemost. 2016;116(4):739-46.

26. Patel MR, Mahaffey KW, Garg J, Pan G, Singer DE, Hacke W, et al. Rivaroxaban versus warfarin in nonvalvular atrial fibrillation. $N$ EnglJ Med. 2011;365(10):883-91.

27. Balla SR, Cyr D, Lokhnygina Y, Becker R, Berkowitz S, Breithardt G, et al. Obesity paradox for stroke in patients with atrial fibrillation treated with rivaroxaban and warfarin in the ROCKET AF trial [abstract]. J Am Coll Cardiol. 2014;63(12):A371.
28. Boonyawat K, Caron F, Li A, Chai-Adisaksopha C, Lim W, Iorio A, et al. Association of body weight with efficacy and safety outcomes in phase III randomized controlled trials of direct oral anticoagulants: a systematic review and meta-analysis. J Thromb Haemost. 2017;15(7):1322-33.

Duane Bates, BSCPharm, ACPR, is a Clinical Pharmacist, Internal Medicine with the Peter Lougheed Center, Alberta Health Services, Calgary Zone, Calgary, Alberta.

Jenny Edwards, BScPharm, ACPR, is a Clinical Pharmacist, Internal Medicine with the Peter Lougheed Center, Alberta Health Services, Calgary Zone, Calgary, Alberta.

Jeffrey Shrum, MD, is a Clinical Lecturer with the Cumming School of Medicine, University of Calgary, Calgary, Alberta.

Casey Chan, MD, is an Internal Medicine Resident with the University of Calgary, Calgary, Alberta.

Sharita Manga is a medical student with the University of Calgary, Calgary, Alberta.

Elizabeth MacKay, MD, MPH, is a Clinical Associate Professor with the Cumming School of Medicine, University of Calgary, Calgary, Alberta.

Competing interests: None declared.

\section{Address correspondence to:}

Duane Bates

Alberta Health Services, Calgary Zone

Peter Lougheed Center

3500 26th Avenue NE

Calgary AB T1Y 6J4

e-mail: duane.bates@ahs.ca

Funding: None received. 